\title{
Pensando a perspectiva linear para além da narrativa eurocêntrica
}

\author{
Vanessa Gonçalves de Almeida Rosa
}

Mestra em Design, Arte e Tecnologia pela Universidade Anhembi Morumbi (2018) e graduada em História da Arte na UERJ (2012), tendo feito intercâmbio na Universidade Paris 8. Atua como artista visual desde 2010, tendo participado de exposiçôes coletivas e individuais, além de projetos diversos principalmente sobre arte pública e multimídias, nas Américas, Ásia, Africa e Europa.

Contato: vanessarosarj@gmail.com

\section{RESUMO}

O artigo traz um questionamento sobre a narrativa mais difundida, sobre o desenvolvimento do método representacional chamado perspectiva linear. Contrapóe-se a leitura de Erwin Panofsky com as teses de Hans Belting e George Saliba, para quem a influência da ciência árabe teria sido fundamental para o Renascimento italiano.

Belting busca comprovar que princípios matemáticos de uma cultura, no caso a particularidade da ótica árabe, podem ser reinterpretados em outra cultura de forma a gerar algo inédito para ambas, exemplificando pela matematização do espaço e dos raios de luz implícita na perspectiva linear. O artigo defende a importância de combinar estudos de História e Teoria da Arte com a História da Ciência.

Palavras-chave: Perspectiva linear; Ótica; História da Ciência; História da Arte

\section{ABSTRACT}

The article questions the most widespread narrative about the development of linear perspective as a representational method. Erwin Panofsky's famous essay on Perspective is opposed to the theses of Hans Belting and George Saliba, who believe that the influence of Arab science and culture was essential for the Italian Renaissance.

Belting seeks to prove that the mathematical principles of a culture, in this case the particularity of Arabic optics, can be reinterpreted in another culture in order to generate something unheard of for both, exemplifying by the mathematization of space and light rays implicit in linear perspective. The article defends the importance of combining studies of History and Theory of Art with the History of Science.

Key-Words: Linear perspective; Optics; Science History; Art History 
Em $1927^{1}$ foi publicado um dos textos mais importantes da História da Arte e dos estudos da imagem, o ensaio "Perspectiva como Forma Simbólica" de autoria do alemáo Erwin Panofsky (1991). A ideia principal do livro é demonstrar o quanto os modos de percepção de cada cultura histórica são diferentes, cada uma constituindo uma visão de mundo própria, expressa em seus modelos de representação imagética. Nossa própria modernidade seria caracterizada por uma particular expressão matemática do conceito de infinito, dentro de uma noção de espaço contínuo e homogêneo (Ibidem, p. 28). O autor foca principalmente na particularidade da perspectiva linear do Renascimento, em relação a modelos representativos anteriores, considerando tal técnica a expressão mais visível de uma profunda transformação do entendimento sobre o espaço e a visão humana por conseguinte, sobre como percebemos a realidade e o lugar do ser humano no mundo.

Imergindo na leitura de Panofsky, vê-se o quanto a perspectiva linear teria sido baseada numa compreensão do espaço físico de forma objetificada, mensurável, calcada numa visão de mundo racionalista e

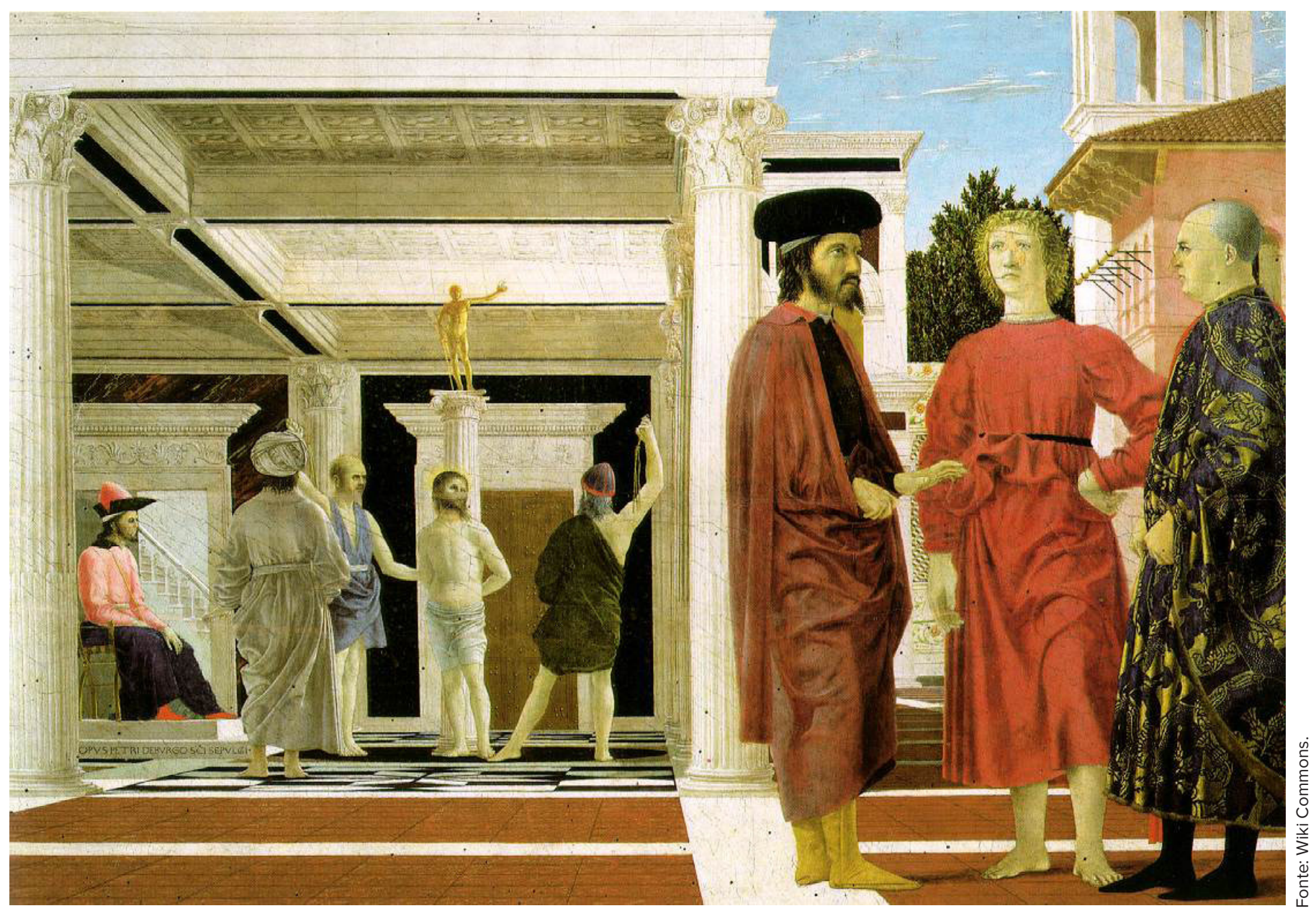

Figura 01: Piero della Francesca (cc. 1415 - 1492), Painel “A Flagelação de Cristo" (cc. 1455-1460). 
tendo o indivíduo como centro. Segundo tal análise, poderia-se mesmo dizer que tal perspectiva, com seu ponto de fuga, seria uma forma mais artificial de representação se comparada às pinturas da antiguidade, pois estas estariam mais próximas da nossa visão esférica da retina, a qual vê sempre as dimensôes de um modo um pouco curvado mesmo onde haveria linhas retas num determinado espaço. Se Panofsky reconhece o desenho em profundidade da Antiguidade como também apresentando uma perspectiva, esta seria outra em relação àquela elaborada na Renascença. Mais que um modelo de representação, a perspectiva linear na interpretação de Panofsky seria um instrumento mediador entre sujeito e realidade, entre desenho de arquitetura e construção final, seria a afirmação de um espaço homogêneo que pode ser organizado em coordenadas, abstração matemática aplicada em tecnologia da representação (NATIVIDADE, 2010, p. 45). Se tornou um lugar comum na história da arte, seguindo a trilha do próprio $\mathrm{Pa}$ nofsky (1991, p. 66), associar a filosofia racionalista e o plano cartesiano do século XVII à perspectiva do século XV e XVI, contrapondo-as aos modelos teocêntricos da Idade Média europeia.

Um dos pontos principais de Panofsky é o quanto a Idade Média teria sido essencial para a elaboração renascentista de uma concepção de espaço contínuo, com uma nova noçáo espacial surgindo apenas depois de se abandonar a representação tridimensional da Antiguidade Clássica, e posteriormente de algum modo se tentar resgatá-la durante o Renascimento italiano - quando já era impossível voltar a mesma visão do mundo clássico. Panosfky defende a teoria de que na História da Arte, quando num complexo cultural um tipo de representação parece não gerar mais grandes novos frutos, ele costuma ser rechaçado pela nova geração, que busca nos modelos e experiências anteriores referências de outros caminhos a seguir. A Idade Média teria rechaçado a Antiguidade e o Renascimento teria voltado a se inspirar na Antiguidade, mas já com o olhar alterado (PANOFSKY, 1991, p. 47).

Tal teórico analisa o desenvolvimento empírico do ponto de fuga, a partir do trabalho de artistas como Giotto e Duccio, e sobretudo Van Eyck no fim da Idade Média. Segundo sua narrativa, Brunelleschi teria ido além ao formalizar a representação do espaço através de leis matemáticas e entendimento da ótica, enquanto Alberti teria sido essencial ao tornar a perspectiva acessível aos artistas, introduzindo um método mais prático para os pintores utilizarem (Ibidem, p. 56-62). Segundo Mario Carpo, Alberti também teria ajudado a desenvolver outros tipos de representação menos ilusivos para os projetos arquitetônicos, pois afinal, a perspectiva linear enquanto desenho técnico não seria suficientemente precisa, mas seria excelente para a concepção projetual (CARPO; LEMERLE, 2008). Para pesquisadores da cultura renascentista, Alberti seria o mais frutífero intelectual da época em termos de teorias da imagem, é em sua homenagem que se fala do 'paradigma albertiano' na arquitetura: a separaçáo entre o ato de desenhar e o ato de construir (CARPO, 2011, p. 44). Na lógica de Alberti, a criação arquitetônica acontecia em sua fase de projeto, só se deveria construir aquilo que se pudesse desenhar, e o desenho, ou melhor, a notação técnica rigorosa do projeto, essa sim seria a obra de arte original. A construção posterior seria uma mera 
cópia, as diferenças entre realidade e projeto seriam imperfeições (Ibidem, p. 26). Para os artistas renascentistas, a perspectiva teria sido essencial por elevar a arte à categoria de ciência, o que melhorava seu status social. Eis o famoso aforismo "La pittura è cosa mentale" (A pintura é coisa mental) de Leonardo da Vinci (DA VINCI, 2011, p. 1).

No entanto, já a tese do historiador e antropólogo visual alemão contemporâneo chamado Hans Belting em seu livro Florenz und Bagdad: eine westöstliche Geschichte des Blicks ("Florença e Bagdad: uma história leste-oeste de olhares", 2008), defende que a perspectiva linear renascentista, ou antes, a mudança no entendimento sobre o espaço e sobre o ato de olhar ocorrida na Europa durante os séculos XV e XVI, estaria diretamente ligada às trocas culturais do ocidente com o mundo árabe. $\mathrm{O}$ autor alemão introduz

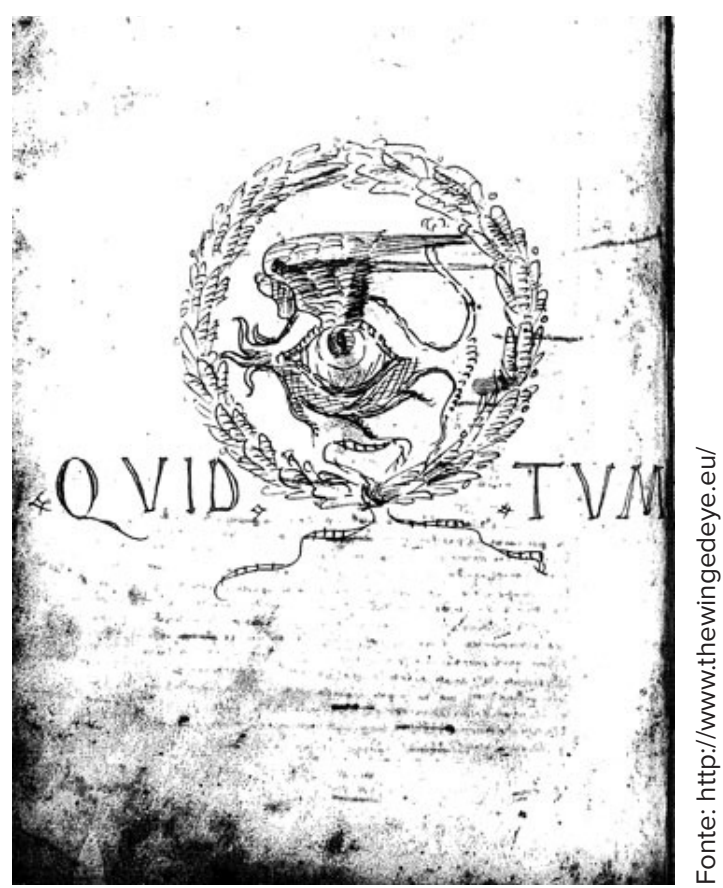

Figura 02: Olho alado de Alberti, século XVI.
"Florença e Bagdad" afirmando que o tema de seu texto é a História do Olhar, a qual teria inicialmente se limitado à cultura ocidental. A menção à Florença no título se refere à Renascença na Itália, quando a noção mais importante de imagem do ocidente teria ganhado forma, ou seja, mais uma vez falamos da perspectiva linear. Bagdad se refere sobretudo à ciência árabe, a cidade como centro simbólico e político do vasto mundo árabe. Um dos pontos centrais do livro de Belting é provar que a arte da perspectiva está fundamentada nos estudos árabes, nos quais teorias matemáticas das linhas de visão e da geometria da luz criaram uma pesquisa ótica muito particular. Belting enfatiza que é importante ir para além da História da Arte, abordando diretamente a História da Ciência.

Uma análise mais abrangente da presença árabe na ciência européia pode ser encontrada na pesquisa do libanês Georges Saliba (2007a), o qual argumenta haver uma teoria "clássica" da história da ciência que diminui a originalidade do mundo árabe ao considerar a pesquisa científica deste como uma continuação do mundo grego, com influências persas e indianas. Em entrevistas (Idem, 2007b) ele conta como a influência da astronomia árabe sobre o mundo ocidental passou a ganhar visibilidade a partir de um acaso, quando em 1957 o historiador da ciência Otto E. Neugebauer encontrou manuscritos de Ibn Shatir na biblioteca Bodleian, em Oxford, Inglater$\mathrm{ra}$, e rapidamente conectou tais escritos às teorias defendidas por Copérnico anos depois da produção destes, conexão, segundo Saliba, até então não discutida pelo meio acadêmico europeu. Ou seja, Saliba questiona quão incipiente ainda é a própria História da Ciência, e quanto trabalho minucioso de um grande contingente de acadêmicos será ne- 
cessário para poderem analisar os documentos que já estão guardados nos próprios acervos europeus, que sequer foram traduzidos do latim ou do árabe ou disponibilizados para o público.

Mas voltemos a questão da perspectiva. O livro já comentado de Hans Belting, busca entender como princípios matemáticos de uma cultura poderiam ter se transformado em imagens figurativas em outra. Quatro capítulos do livro são destinados às discussôes em torno da teoria ótica árabe, principalmente a partir da base do trabalho de Ibn al-Haytham, conhecido no Ocidente como Alhazen, filósofo e matemático árabe que viveu no Cairo durante o século XI. Tratava-se então de uma racionalização da capacidade visual através do uso da geometria. $\mathrm{O}$ trabalho de Alhazen já seria conhecido na Europa durante a Idade Média, o próprio termo "perspectiva" teria passado a ser usado após traduzirem para latim no século XIII, na Espanha, seu tratado de sete volumes sobre ótica; logo na primeira tradução latina o trabalho ganhou o título de "Perspectiva" (também chamado de "De Aspectibus", traduzido por aspecto ou aparência), o qual foi alterado na edição feita com a prensa moderna do século XVI para "Livro da Ótica" (BELTING, 2008, p. 9).

Belting apresenta então, uma história intelectual da recepção do pensamento de Alhazen no Ocidente, desde sua tradução. $\mathrm{O}$ inglês franciscano Roger $\mathrm{Ba}$ con no século XIII foi um grande entusiasta das teorias do filósofo árabe, se tornando famoso por sua defesa do conhecimento e experimentação empírica, dando grande relevância ao estudo da ótica. Bacon e John Pecham, entre outros, passaram a ser conheci- dos como 'perspectivistas'. No entanto, outros escolásticos se contrapuseram veementemente a Bacon e aos intelectuais que seguiam ideias parecidas com as suas, havia uma intensa polêmica em torno do quanto a visão poderia ser fonte de conhecimento. Para o mundo teocentrado da Idade Média europeia tal proposição era uma blasfêmia, pois apenas a inspiração divina ou a palavra bíblica de Deus poderia ser fonte de conhecimento válido. Atribuir ao sentido da visão uma fonte digna de conhecimento teria sido parte de uma mudança antropológica, algo que segundo Belting já se tornava visível com o crescente naturalismo da arte europeia nos séculos antecessores à invenção da perspectiva linear (Ibidem, p.150). Tal história intelectual sobre a recepção de Alhazen já era descrita no artigo do historiador da ciência americano David C. Lindberg (1967), "Alhazen's theory of vision and its reception in the west" (A teoria da visão de Alhazen e sua recepção no oeste), desde então considerado uma referência na história da ótica (TOSSATO, 2005). Segundo Lindberg, o livro "Perspectiva" de Vitélio, que seria um compêndio sobre ótica reunindo as ideias desde Euclides e Ptolomeu até Al-Kind, Alhazen e Bacon, tinha o status de livro oficial para o ensino da ótica nas Universidades europeias do século XIV e XV (LINDBERG, 1976, p. 118).

Segundo o pesquisador Claudemir Roque Tossato (2005), as teorias gregas dividiam-se entre a concepção anatômica (Galeno), matemática (Euclides e Ptolomeu) e filosófica da visão, e dentro da noção filosófica ainda haveria a divisão entre as ideias de intromissão (olho como receptor, como os atomistas defendiam) e emissão (olho como emissor de raios de visão, Platão e Aristóteles). A contribuiç̧ão 
de Alhazen teria desenvolvido muito a teoria da intromissão desmistificando os raios visuais, discutindo ótica enquanto construção geométrica da luz, além de conseguir combinar as abordagens anatômicas, filosóficas e matemáticas no mesmo tratado (LINDBERG, 1967 , p. 322). A narrativa de Belting distingue-se da maior parte das pesquisas sobre história da ótica por valorizar mais a originalidade do pensamento árabe, evitando compreendê-la como uma continuidade das ideias gregas. Belting referencia o trabalho de Georges Saliba, tentando ser atento justamente às características culturais árabes que partiam de uma noção cosmológica distinta do mundo grego. A tese de Belting é que tais características, em especial o papel da luz enquanto elemento transcendental no mundo árabe, teria permitido uma interpretação própria sobre visão que não teria sido possível na cultura ocidental sempre tão focada em imagens.

Apesar de manter os aspectos fundamentais da anatomia do olho criada por Galeno e as noçóes de cone visual de Euclides, Alhazen entenderia a visão mais em termos de luz do que de corpos e objetos (BELTING, 2008, p. 114). Ele afirmava que a luz precisaria sim de algum tipo de corpo físico, mas ela teria propriedades particulares em relação a outros fenô-

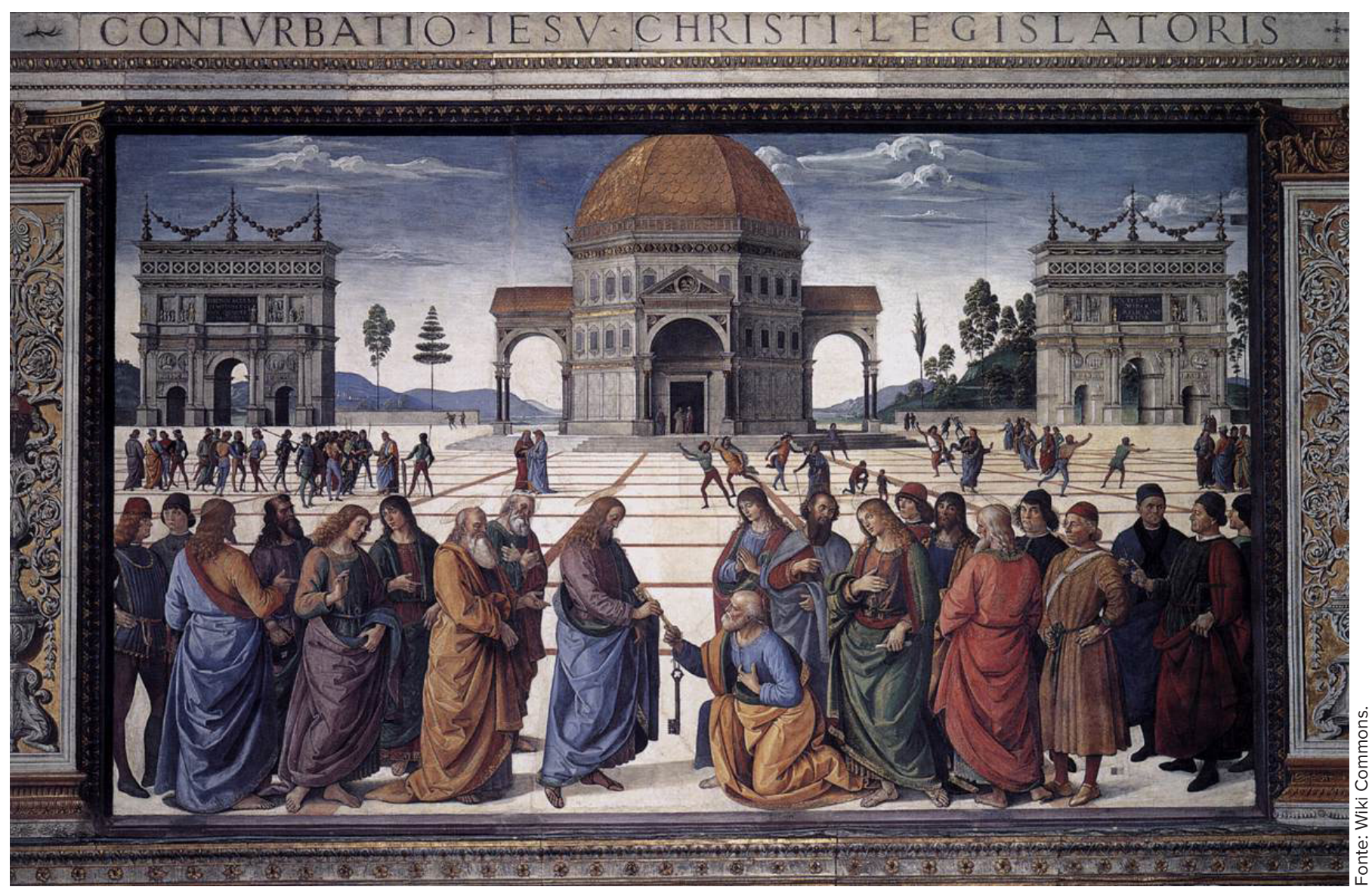

Figura 03: Afresco de Pietro Perugino (c. 1448-1523). Entrega das Chaves fresco, 1481-1482, Capela Sistina, Rome. 
menos naturais, teria sua presença no mundo fisico através de linhas, de raios de luz geométricos, e estes poderiam ser adequadamente medidos matematicamente. Através da leitura de Hans Belting mas também de teóricos árabes da arte como Seyyed Hossein Nasr (2015), se torna evidente que a luz para a cultura islâmica tem uma característica transcendental essencial, pois enquanto as imagens sensíveis carregariam as ilusôes do mundo transitório, a luz revelaria a harmonia divina subjacente à realidade. Nas palavras de Nasr $(2015$, p. 7), a cultura e a arte islâmica só pode ser compreendida através da sua espiritualidade específica, esta seria fruto de uma religiáo muito mais interessada na harmonia cosmológica do mundo do que nas histórias detalhadas de homens e santos tanto narradas pela arte cristã ${ }^{2}$.

Alhazen não se interessaria tanto pelas imagens quanto pelos pontos de luz e como poderiam ser medidos (BELTING, 2008, p. 105). Para isso, desenvolve uma série de aparelhos, instrumentos para testar o comportamento da luz, tais como câmeras escuras. Chegou a conclusão de que a luz atravessa corpos translúcidos de pouca densidade, como o ar e a luz, sentindo refração entre densidades distintas, enquanto é refletida pelos corpos opacos, que são entáo iluminados e rebatem os raios de luz segundo leis matemáticas (Ibidem, p. 113). Nossos olhos então, receberiam inúmeros raios numa certa ordem, o que geraria uma impressão sensória a qual é por sua vez interpretada como imagem pelo nosso cérebro. Um dos volumes de seu tratado é voltado para a psicologia da visão. Separa visão, luz e olho de visualidade, que seria um processo psicológico - nosso cérebro estaria constantemente interpretando imagens para não ser iludido, um processo entendido como cultural e fisiológico pelo filósofo (Ibidem, p. 124) ${ }^{3}$.

O olho, então não emitiria qualquer tipo de luz, mas seria um receptor. A teoria de Alhazen reconhece que nosso olho funcionaria de modo semelhante à câmera escura. Este ponto é de grande interesse se lembrarmos da pesquisa de outro influente teórico e historiador contemporâneo especializado na questão da visão e da imagem, Jonatham Crary, que argumenta em seu livro "Técnicas do Observador"(1992), o quanto o modelo epistemológico sobre a visão, prevalecente até o final do século XVIII na Europa, era baseado na metáfora de um olho como uma câmera escura. No século XIX aspectos fisiológicos e psicológicos da visão passaram a ganhar uma atenção diferenciada, o que teria influenciado, segundo Crary, o desenvolvimento de diversos aparelhos técnicos para iludir o olho, entre os quais a fotografia seria um dos menos tridimensionais ${ }^{4}$. Portanto, seguindo a lógica da tese de Belting, mesmo que homens como Kepler e Descartes tenham feito importantes contribuições no estudos sobre lentes e anatomia do olho, descobrindo o papel da retina, o modelo de visáo sustentado por Alhazen teria permanecido.

O que interessa principalmente para Belting é a matematização do olhar e da luz feita por Alhazen, assim como o quanto tal processo estaria muito ligado ao seu contexto cultural, a um mundo que dava muito menos importância às imagens do que o Ocidente. $\mathrm{O}$ tratado de ótica de Alhazen não foi utilizado para criar um espaço visual ou debater modelos representativos, mas voltado para a beleza presente no entender o comportamento da luz no mundo 
natural (BELTING, 2008, p. 39). A teoria da visão de Alhazen seria fruto do mesmo meio cultural em que a aparência física da arquitetura e da arte era dominada pela matemática. Segundo Belting, seria na troca entre diferentes civilizaçôes que algumas das maiores mudanças teóricas se tornariam possíveis. Afinal, no próprio processo de tradução do tratado de ótica teria ocorrido uma reinterpretação do filósofo árabe, com diversos termos latinos de sentido figurativo sendo empregados para traduzir palavras árabes que falavam de luz, rastros ou marcas, mas não de imagens (Ibidem, p. 147).

Avançando na narrativa de Hans Belting, já no século XV, chegamos a Biagio Pelacani de Parma, um teórico que teria sido muito influente nos círculos do proto renascimento incluindo o meio social do próprio Brunesllechi, um teórico que teve seu trabalho intitulado "Questóes de Perspectiva" copiado por um escriba florentino em 1428. Pelacani foi um grande estudioso de Alhazen mas também de Vitruvius, que começava a ser conhecido pelos italianos. Sua maior contribuição seria passar a considerar que não somente os objetos, mas o espaço entre eles, o vazio deveria ser quantificável - esta teria sido a pri- meira vez que se o espaço vazio é introduzido como elemento de uma teoria da visão, o que é interpretado pelo historiador alemáo como uma incorporação do caráter abstrato da luz das teorias de Alhazen dentro da noção ocidental de imagem (Ibidem, p. 162). Segundo Belting, o trabalho desse homem teria sido o fundamento da ideia de espaço matemático por trás da obra de Brunelleschi, a visão sendo enaltecida como fonte essencial de conhecimento. Das grandes polêmicas medievais sobre a possibilidade de conhecer empiricamente, chega-se então ao olho enquanto símbolo do conhecimento na Renascença. Belting debate tal questão principalmente através da figura de Alberti, quem tinha um olho alado em chamas como emblema pessoal. $\mathrm{O}$ autor alemáo ainda traz à tona o quanto mitos da Antiguidade foram reinterpretados durante a Renascença, chegando ao ponto de mudar completamente seus finais, pois se o olhar na Antiguidade era frequentemente algo ameaçador nas histórias, na Renascença ele era empoderador. Na narrativa do próprio Alberti sobre Narciso, este não afoga-se olhando seu reflexo, mas encontra na sua imagem a própria arte. Narciso se tornaria uma flor sobre a água, e segundo Alberti, teríamos em tal conto uma metáfora para a origem da pintura (Ibidem, p. 247).

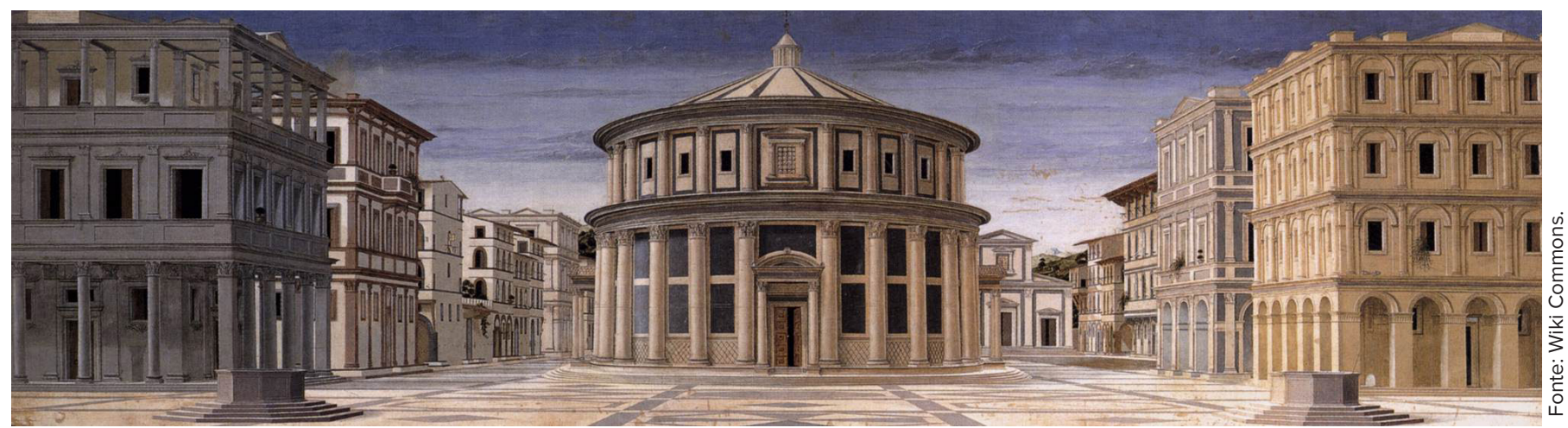

Figura 04: Formerly Piero della Francesca - Ideal City - Galleria Nazionale delle Marche Urbino. 
A Renascença teria sido grandemente influenciada tanto pelos textos clássicos quanto por suas trocas com outras culturas, principalmente o mundo árabe, com quem suas relaçóes diplomáticas e religiosas nem sempre eram muito calorosas. Era preferível então se diferenciar dos povos vistos como infiéis ao reivindicar ser a herdeira da antiguidade greco-romana, mesmo que fizesse uma livre interpretação desta, incluindo seu paganismo (Ibidem, p. 230). Diversos artistas italianos do século XVI afirmavam que Vitruvius já se referia à perspectiva, que ela já existiria na Antiguidade Clássica e eles apenas a retomavam, apesar de que Alberti tenha reconhecido não ser possível inferir as noções de perspectiva linear das parcas descrições de desenhos arquitetônicos presentes na obra romana "De Architectura" (BELTING, 2008 e CARPO, 2011). A interpretação da noção de proporção de Vitruvius ganhou também um lugar de destaque nas relaçooes entre arte e matemática (PICON, 2011, p.30).

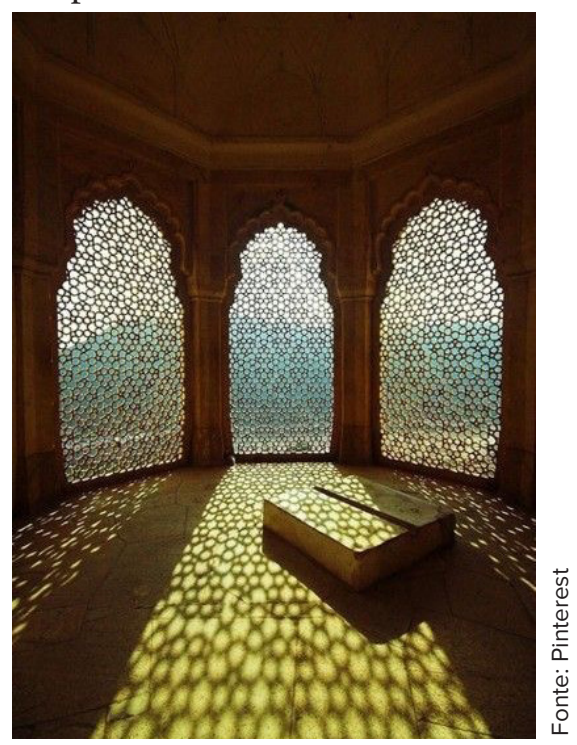

Figura 05: Janela de treliça, parte do conservatório de Amer Fort, cidade de Amer, India, construido no século $X V I$.
A perspectiva seria sobretudo uma forma de dirigir o olhar. No caso árabe, a janela de treliça teria como finalidade colocar em cena a própria luz como forma simbólica ${ }^{5}$ a janela de luz purificaria o olhar das imagens do mundo exterior e protegeria o interior dos olhares externos, mostraria a luz em seu estado essencial. Hans Belting contrapóe a ideia de janela de luz oriental com a janela do olhar (para fora) ocidental. Ocidente: sujeito se torna ativo com o olhar, cria-se uma geometria representativa com a perspectiva. Oriente: ele vê e vivencia a luz, um poder que vai além do indivíduo, como um espetáculo cósmico, a arte e a arquitetura se baseiam numa representação da própria geometria. Diferenciar culturas se torna uma ocasião para conseguir interpretar, para reconhecermos aquilo que tomamos como óbvio, mas que provém de uma determinada bagagem cultural (BELTING, 2008, p. 272).

Vários outros recortes de pesquisas fazem contribuiçôes semelhantes às de Hans Belting, como os intelectuais que criam outros eixos de narrativa ao se focar na importância das trocas entre civilizaçôes e grupos diversos como propulsionadoras das transformaçóes culturais de cada período. Pode-se narrar séculos a partir das Rotas da Seda (ELISSEEFF, 1998 e FRANKOPAN, 2016), ou explicar o capitalismo e as técnicas de vigilância a partir da experiência dos grandes latifúndios nas colônias americanas, como faz Nicholas Mirzoeff, grande expoente contemporâneo dos estudos visuais nos Estados Unidos (MIRZOEFF, 2011). Segundo Saliba (2007b), o que teria permitido um crescimento acelerado das ciências europeias a partir do século XVI não seria tanto características próprias da Europa enquanto modelo 


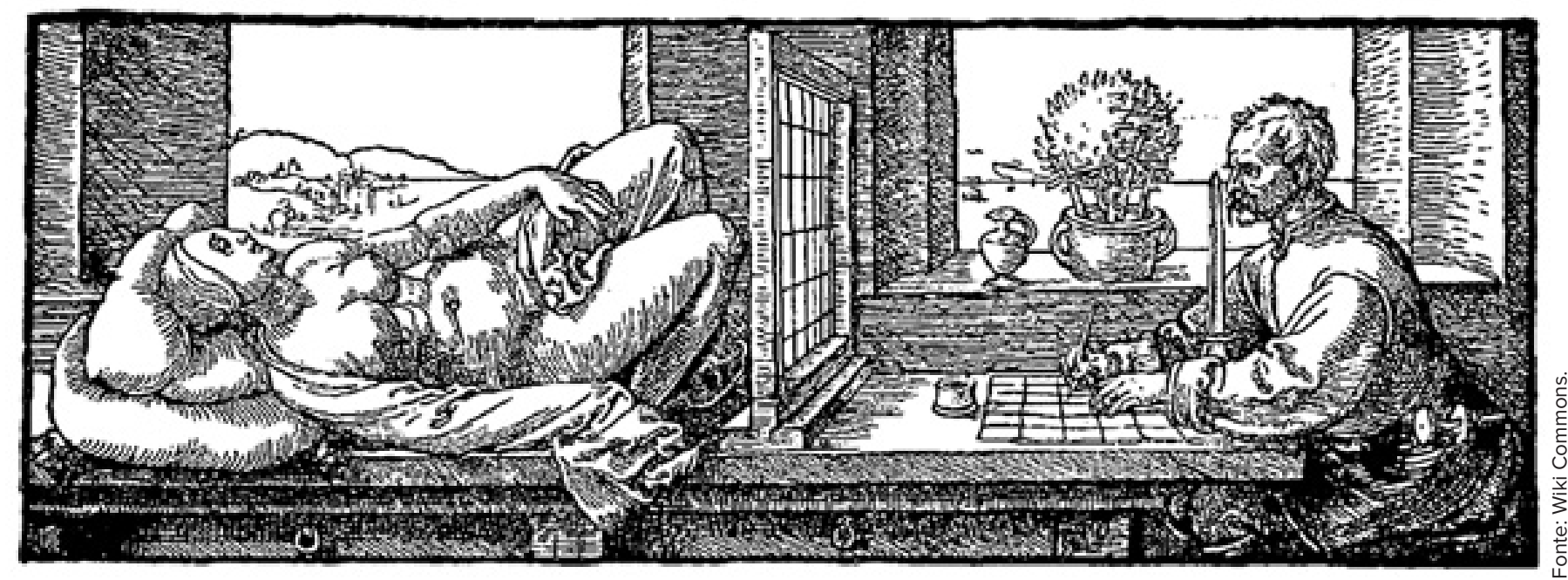

Figura 06: Der Zeichner des liegenden Weibes, in: Underweysung der Messung mit dem Zirckel und Richtscheyt (auch: Emotivität des Weibes). Ilustração de livro (1512-1525).

de civilização, sequer suas escolhas religiosas posteriores à Renascença (e neste ponto Saliba lembra da Inquisição e a Contra Reforma), mas o enorme fluxo de ouro e mercadorias oriundas das Américas que deram à Europa vantagens significativas em relação não apenas ao mundo árabe, mas a todas as outras civilizaçôes durante quatro séculos. Para tal pesquisador libanês, uma das consequências mais complexas deste fenômeno é que as próprias instituiçóes acadêmicas árabes de hoje se mostram mais céticas em relação a sua história do que o público dos grandes centros universitários americanos, pois as teorias dos orientalistas europeus do século XIX teriam convencido os árabes de uma determinada narrativa histórica sobre si mesmos (SALIBA, 2007a, 2007b).

Isto é algo importante de ser lembrado pois, considerando que o século XXI se anuncia como uma época em que a supremacia econômica europeia já é passado, e mesmo os EUA não seriam mais um líder incontestável das relaçôes de poder globais, além de que as grandes potências cada vez se tornam mais multiculturais com os fluxos migratórios, se quisermos nos atentar para as mudanças atuais protagonizadas pela lógica do digital, seria importante não mantermos nossos olhos restritos a narrativas geograficamente tão específicas. Principalmente agora que as instituiçôes voltadas à pesquisa e ao desenvolvimento tecnológico estão integradas em redes globais de compartilhamento de informaçóes. As grandes universidades se tornam necessariamente internacionais, mesmo em seu quadro docente, mas principalmente na proporção crescente de alunos estrangeiros, oriundos de cada vez mais países. Como então não adaptar nossa narrativa e a referência ao Renascimento ao contexto muito mais complexo das trocas entre várias civilizaçôes?

Sustenta-se então nesta pesquisa, que para darmos conta do simbolismo subjacente a nossos modelos e métodos representacionais, ou a nossas concepçóes de espaço, é importante também sabermos contextu- 
alizar os referenciais teóricos que estão nas bases de nossa formação acadêmica e nosso olhar crítico sobre o mundo. Afinal, tomando o exemplo da História da Arte, o quanto esta não teve seu corpus teórico em grande parte desenvolvido por determinados grupos de europeus, sobretudo os de língua alemâ? A história da História da Arte enquanto disciplina acadêmica, que tem mais consenso entre pesquisadores hoje (BAZIN, 1989), parte da figura do arqueólogo alemão apaixonado pela Grécia antiga (como quase todo intelectual alemão do século XVIII) chamado Winckelmann, para depois ser aprofundada com o suíço Jacob Burckhardt e sua noção de indivíduo moderno como algo nascente durante o Renascimento, seguido pelo também suíço Heinrich Wölfflin e seu extremo formalismo que foi contraposto pelas teorias do austríaco Alois Riegl. Warburg e Cassirer, dois mentores de Panofsky, se contrapu- nham às teorias de Burckhardt e Wölfflin, e ambos, como outros intelectuais de sua época, passaram a ser influenciados pelos estudos modernos de antropologia sobre as colônias europeias, tendo os dois se interessado pelas culturas ameríndias e línguas africanas para desenvolverem suas teorias - nesse ponto, Belting apresenta uma continuidade quanto a abordagem e tendência intelectual de seus predecessores da antropologia visual.

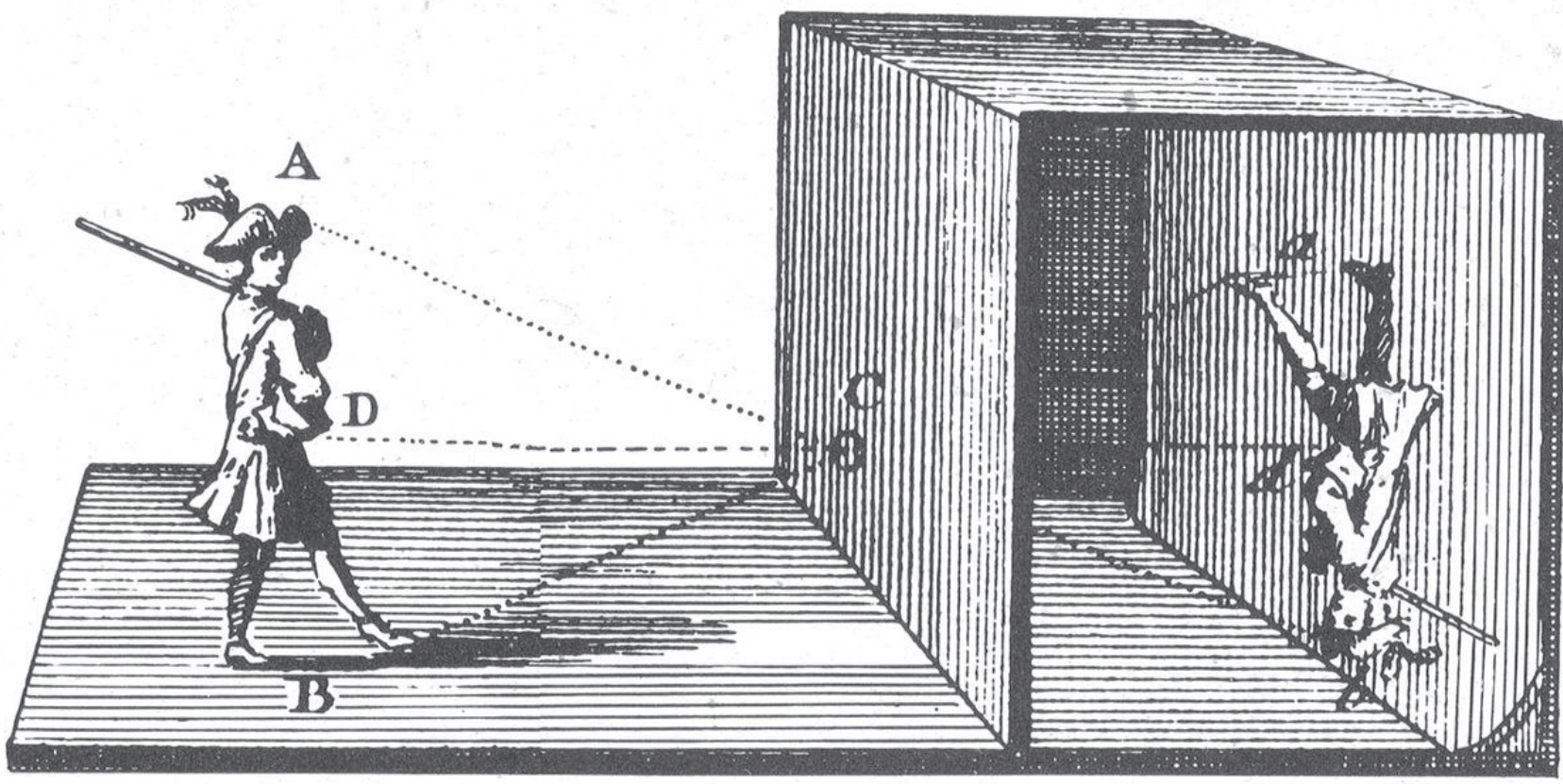

Figura 07: Autor desconhecido, ilustração sobre camera obscura. século XVIII (não confirmado). 


\section{Notas de fim:}

1. Este mesmo texto já havia aparecido na publicação interna da Biblioteca Warburg em 1924, mas sua publicação mais conhecida e difundida foi lançada em 1927 (ALLOA, 2015, p. 51).

2. Existem histórias no Quran, algumas até relativas a personagens bíblicos, no entanto elas se focam mais no significado espiritual dos eventos do que em seus detalhes. De modo semelhante, a análise de manifestações artísticas islâmicas feita por Nars se volta principalmente a seus significados cosmológicos.

3. Tais consideraçóes de Alhazen são comentadas por Lindberg, Tossato e Belting, no entanto, os dois primeiros reconhecem a psicologia da visão para Alhazen como um limitador de sua teoria que teria sido suplantado por Kepler, enquanto Belting se interessa pelas diferenças culturais acerca de imagens que transparecem através das ideias de Alhazen.

4. A fotografia teria se tornado o método preponderante de sua época, segundo Crary, devido a sua similaridade aos modelos representativos da pintura. Panofsky (1991, inicialmente publicado em 1927), Berger (1972) e Belting (2008) também reconhecem a fotografia como uma continuação do modelo de visão e fruição da imagem já apresentado pela perspectiva linear.

5. Belting escreve que prefere seguir a noção de Cassirer e não a de Panofsky em relação ao conceito "forma simbólica", apesar dele tampouco parecer muito preocupado em ser rigoroso no uso do termo. No entanto, considerando que Cassirer não se refere diretamente à perspectiva linear, segundo Belting, seria a arte renascentista, a qual passa a ser marcada pelo modelo representativo da perspectiva, que poderia ser interpretada como um símbolo da modernidade (BELTING, 2008, p. 229).

\section{Referências Bibliográficas:}

ALBERTI, L. B. Da pintura. Campinas: Edunicamp, 1989.

ALLOA, Emmanuel. Could perspective ever be a symbolic form? Revisiting Panofsky with Cassirer. In: Journal of Aesthetics and Phenomenology, v.2, n.1, pp. 51-72. London: Bloomsbury Publishing Plc, 2015.

2010.

(org). Penser l'image. Paris: Les presses du réel,

BAZIN, Germain. A História da História da Arte. São Paulo: Martins Fontes, 1989.

BELTING, Hans. Florenz und Bagdad: eine westöstliche Geschichte des Blicks. Munique: Beck, 2008.

Florence and Baghdad: Renaissance art and Arab science. Cambridge: Belknap Press of Harvard University Press, 2011.

An anthropology of images: picture, medium, body. Princeton: Princeton University Press, 2011.

CARPO, Mario. The Alphabet and the Algorithm. Cambridge: The MIT Press, 2011.

; LEMERLE, Frédérique (org). Perspective, projections and design: technologies of architectural representation. London: Routledge, 2008.

CASSIRER, Ernst. The philosophy of symbolic forms v.1. New Haven: Yale University Press, 1996.

The problem of the symbol and its place in the system of philosophy (1927). In: Continental Philosophy Review, Man and World. New York: Springer, setembro 1978, v. 11, n.3, p. 411-428.

The Warburg years (1919-1933): essays on language, art, myth, and technology. New Haven: Yale University Press, 2013.

CRARY, Jonathan. Techniques of the observer. London: MIT Press, 1992.

FRANKOPAN, Peter. The Silk Roads - A New History of the World. New York: Penguin Books (Vintage Editions), 2017.

LINDBERG, D. C. Alhazen's theory of vision and its reception in the west. In: Isis, v.58, p. 321-41, 1967.

MIRZOEFF, N. Entrevista con Nicholas Mirzoeff: La cul- 
tura visual contemporánea: política y pedagogía para este tiempo [2011].

PANOFSKY, Erwin. Perspective as symbolic form. New York: Zone Books, 1991.

Studies in Iconology: Humanistic Themes in the Art of the Renaissance. Oxford: Icon Editions, 1972.

ROQUE TOSSATO, Claudemir. $A$ função do olho humano na óptica do final do século XVI. In: Scientle Studia. São Paulo, SP, v. 3, n. 3, 2005.

SALIBA, Georges. Islamic Science and the Making of the European Renaissance. Cambridge: MIT Press, 2007.

WARBURG, Aby. Lê Rituel du Serpent. Paris: Macula, 2003. 